\section{Microscopy Today Innovation Awards}

Congratulations to the winners of the eighth annual Microscopy Today Innovation Awards competition. These awards honor innovative microscopy-related products and methods that appeared in the previous year.

Our team of judges, led by Tom Kelly, looked for innovations that will make new scientific investigations possible. The ten winning innovations were selected on the basis of their importance and usefulness to the microscopy community. The entries most likely to win are those that provide better or entirely new methods of analysis using some type of microscope or microanalytical instrument.

The 2017 Microscopy Today Innovation Award winners are:

Aalto University (Finland) for the black-silicon induced-junction silicon photodiode

Bruker-Hysitron for NanoScratch in-situ nanomechanical testing in the SEM

Keyence Corporation of America for the VR-3000 non-contact wide-area 3D measurement system

University of Missouri for the plasmonic grating platform to replace glass slides

University of Newcastle (Australia) for the scanning helium atom microscope

Oak Ridge National Laboratory and the University of Uppsala (Sweden) for a STEM method to observe magnetic ordering with atomic resolution

Phasefocus for the Livecyte ${ }^{\circledR}$ Kinetic Cytometer to analyze live cell populations

Scripps Institution of Oceanography for the benthic underwater microscope

University of Washington and Shenzhen Institutes of Advanced Technology for scanning thermo-ionic microscopy

Yale University for multimodal imaging using a coherence switching laser

Descriptions of the above innovations are given in an article within this issue. Nomination applications for the next competition are available upon request (charles.lyman@lehigh.edu). The deadline for the next competition is March 21, 2018.

Charles Lyman

Editor-in-Chief

Publication Objective: to provide information of interest to microscopists.

Microscopy Today is a controlled-circulation trade magazine owned by the Microscopy Society of America that is published six times a year in the odd months. Editorial coverage spans all microscopy techniques including light microscopy, scanning probe microscopy, electron microscopy, ion-beam techniques, and the wide range of microanalytical methods. Readers and authors come from both the life sciences and the physical sciences. The typical length of an article is about 2,000 words plus figures and tables; feature articles are longer. Interested authors should consult "Instructions for Contributors" on the Microscopy Today website: www.microscopy-today.com.

\section{ISSN 1551-9295}

\section{Disclaimer}

The Microscopy Society of America and the editors cannot be held responsible for opinions, errors, or for any consequences arising from the use of information contained in Microscopy Today. The appearance of advertising in Microscopy Today does not constitute an endorsement or approval by the Microscopy Society of America of any claims or information found in the advertisements. By submitting a manuscript to Microscopy Today, the author warrants that the article is original or that the author has written permission to use copyrighted material published elsewhere. While the contents of this magazine are believed to be accurate at press time, neither the Microscopy Society of America, the editors, nor the authors can accept legal responsibility for errors or omissions.

\section{Editorial Staff}

Charles E. Lyman, Editor-in-Chief charles.lyman@lehigh.edu (610) 758-4249

Gennifer Levey, Production Manager glevey@meridianartpro.com

(212) 780-0315

Ron Anderson, Executive Editor randerson20@tampabay.rr.com Phil Oshel, Technical Editor oshellpe@cmich.edu

Robert Price, Associate Editor

bob.price@uscmed.sc.edu

Stephen Carmichael, Columnist carmichael.stephen@mayo.edu Eric Clark, Pioneers Editor eclark@magnet.fsu.edu

Richard Edelmann, Education Editor edelmare@miamioh.edu

Deb Kelly, Microscopy 101 Editor debkelly@vt.edu

Thomas E. Phillips, Consulting Editor phillipst@missouri.edu

Paul Webster, Calendar Editor p.webster@oak-crest.org

John Shields, Humor Editor jpshield@uga.edu

Nikolaus Cordes, Digital Content Editor ncordes@lanl.gov

Thomas Kelly, Chief Awards Judge

Thomas.kelly@ametek.com

Advertising Sales

M.J. Mrvica Associates, Inc

2 West Taunton Avenue, Berlin, NJ 08009 mimrvica@mrvica.com

(856) 768-9360

Kelly Miller, Account Manager

kmiller@mrvica.com

Magazine website:

http://www.microscopy-today.com

Free subscriptions are available

Publisher

Cambridge University Press

One Liberty Plaza, 20th Floor

New York, New York 10006

(212) 337-5000

Circulation: 18,000

Editorial Board

Arlan Benscoter, Lehigh University John Bozzola, Southern Illinois University Peter Crozier, Arizona State University

Vinayak Dravid, Northwestern University

David Grubb, Cornell University

Bryan Huey, University of Connecticut

Heather Lowers, U.S. Geological Survey

John Mackenzie, North Carolina State Univ.

Paul Maddox, U. of North Carolina-Chapel Hill

Ania Majewska, U. Rochester Med School

Joseph Michael, Sandia National Labs

Caroline Miller, Indiana University

Brian M. Patterson, Los Alamos National Lab

John Reffner, John Jay College, SUNY

Ian Robertson, University of Wisconsin

Phillip Russell, Appalachian State University

Glenn Shipley, Citizen Microscopist

Robert Simmons, Georgia State University

Bradley Thiel, SUNY Polytechnic Institute

Paul Voyles, University of Wisconsin

Simon Watkins, University of Pittsburgh

Cynthia Zeissler, Nat. Inst. of Stds. and Tech. (NIST) 